\title{
Hubungan antara kualitas tidur dengan excessive daytime sleepiness pada pekerja bergilir
}

\author{
Luthfi Aziz ${ }^{1}$, Adi Hidayat ${ }^{2}$
}

\begin{abstract}
ABSTRAK
\section{LATAR BELAKANG}

Pekerja bergilir (shift workers) banyak dijumpai pada masyarakat industri dan mempunyai efek yang negatif terhadap kualitas tidur. Excessive daytime sleepiness (EDS) adalah gejala dari gangguan tidur berupa rasa kantuk pada siang hari yang berlebihan hingga mengganggu aktivitas. Gejala ini dapat menimbulkan dampak merugikan bagi pekerja dan perusahaan. Kualitas tidur, kerja shift, gaya hidup, usia dan jenis kelamin merupakan faktor risiko dari EDS. Seorang pekerja bergilir yang mengalami EDS memiliki risiko kecelakaan kerja yang tinggi. Penelitian ini dilakukan dengan tujuan untuk menentukan hubungan antara kualitas tidur dan EDS pada pekerja bergilir.
\end{abstract}

\section{METODE}

Studi ini menggunakan desain cross-sectional dengan jumlah subjek penelitian sebanyak 57 pekerja bergilir. Pengumpulan data mengenai usia dan jenis kelamin dilakukan dengan menggunakan kuesioner. Kualitas tidur diukur dengan kuesioner Pittsburgh sleep quality index (PSQI) dan Excessive daytime sleepiness (EDS) diukur dengan Epworth sleepiness scale (ESS). Data dianalisis menggunakan uji korelasi Spearman dan uji Mann Whitney.

\section{HASIL}

Hasil uji normalitas menunjukkan data yang dikumpulkan tidak tersebar secara normal. Nilai median subjek pekerja besarnya 27 tahun dan sebagian besar subjek adalah laki-laki sebanyak $44(77.1 \%)$ orang. Tidak didapatkan perbedaan yang bermakna antara jenis kelamin dan EDS ( $\mathrm{p}=0.396)$. Didapatkan hubungan yang sedang dan bermakna antara kualitas tidur dan $\operatorname{EDS}(\mathrm{r}=0.545 ; 0=0.000)$. Usia subjek tidak berhubungan secara bermakna dengan $\operatorname{EDS}(\mathrm{r}=0.124 ; \mathrm{p}=0.359)$.

\section{KESIMPULAN}

Penelitian ini menunjukkan hubungan bermakna antara kualitas tidur dan excessive daytime sleepiness pada pekerja, tetapi tidak terdapat perbedaan nilai median EDS antara laki-laki dan perempuan.

Kata kunci: excessive daytime sleepiness, kualitas tidur, pekerja bergilir
${ }^{1}$ Program Studi Kedokteran, Fakultas Kedokteran Universitas Trisakti

${ }^{2}$ Departemen Ilmu Kesehatan Masyarakat, Fakultas Kedokteran Universitas Trisakti

\section{Korespondensi:}

Adi Hidayat

Departemen Ilmu Kesehatan

Masyarakat, Fakultas Kedokteran

Universitas Trisakti,

Jalan Kyai Tapa No. 260, Grogol, Jakarta Barat 11440

Email: hidayat.adi@trisakti.ac.id

J Biomedika Kesehat 2019;2(4):144148

DOI: 10.18051/JBiomedKes.2019. v2.144-148

pISSN: 2621-539X / eISSN: 2621-5470

Artikel akses terbuka (open access) ini didistribusikan di bawah lisensi Creative Commons Attribution 4.0 International (CC-BY 4.0) 


\section{ABSTRACT}

\section{Relationship between sleep quality and excessive daytime sleepiness in shift workers}

\section{BACKGROUND}

Shift workers is highly prevalent in industrialized societies, it has pronounced negative effects on sleep. Excessive daytime sleepiness (EDS) is a symptom of sleep disorders in form of abnormal sleepiness thus ruin daytime activities. These symptoms can have a detrimental impact on workers and companies. Sleep quality, shift work, lifestyle, age and gender are the risk factors of EDS. A shift worker who has EDS has a high risk of workplace accidents. The objective of this study was to determine the relationship between sleep quality and excessive daytime sleepiness among shift workers.

\section{METHODS}

This study was a cross-sectional study design involving 57 workers. A questionnaire was used to collect data on age and gender.The sleep quality was measured using the Pittsburgh Sleep Quality Index (PSQI) questionnaire and EDS using the Epworth sleepiness scale (ESS). Data were analyzed using the Spearman correlation test and the Mann Whitney test.

\section{RESULT}

The normality test results showed the data was not normally distributed. The median age was 27 years and mostly $44(77.1 \%)$ subject was male There was no significant difference between gender and EDS $(p=0.396)$. There was a moderate correlation between sleep quality and EDS (r: 0.545; p: 0.000). And age was not significantly correlated with EDS (r: 0.124; p: 0.359).

\section{CONCLUSION}

This study demonstrated that there was a significant relationship between sleep quality and excessive daytime sleepiness in shift workers, while there is no difference in the median EDS values between men and women.

Keywords: excessive daytime sleeping, sleep quality, shift workers

\section{PENDAHULUAN}

Kerja bergilir (shift work) adalah jadwal kerja yang tidak standar termasuk di antaranya bertugas di malam hari, rotasi kerja siang dan malam, kerja malam yang permanen dan pekerjaan yang memerlukan pekerja untuk bangun di tengah malam. ${ }^{(1)}$ Menurut International Labour Organization (ILO) pekerja bergilir (shift workers) adalah pekerja yang bekerja secara bergiliran dengan metode organisasi waktu kerja di mana pekerja bergantian satu sama lain di tempat kerja sehingga proses kerja dalam sebuah pabrik dapat beroperasi lebih lama daripada jam kerja individu pada jam harian dan malam yang berbeda. ${ }^{(2)}$ Pekerja bergilir malam yang terbiasa tidur lebih sedikit dan harus bekerja pada titik terendah pola sirkadian seringkali mengalami kekurangan tidur pada siang hari. ${ }^{(3)}$ Sebuah studi di New York pada 3345 subjek menunjukkan bahwa pekerja yang bekerja shift malam dan rotasi kerja, sebanyak $20 \%$ mengalami excessive daytime sleepiness (EDS). ${ }^{(4)}$

Excessive daytime sleepiness menurut American Sleep Association adalah kemampuan seseorang untuk tetap tidak mudah tertidur dan senantasa terjaga selama masa seseorang tidak tertidur. ${ }^{(5)}$ Sebuah penelitian menunjukkan proporsi terjadinya EDS pada perawat yang bekerja shift lebih tinggi secara bermakna dibandingkan perawat yang tidak bekerja shift. ${ }^{(6)}$

Berbagai faktor dapat menyebab terjadinya EDS antara lain gangguan psikiatri, kelainan neurologi, paru-paru, jantung, kualitas tidur dan kuantitas tidur. ${ }^{(7)}$ Tidur merupakan proses psikologis yang penting bagi kehidupan. Secara definisi tidur adalah masa istirahat untuk tubuh dan pikiran, di mana selama masa ini kemauan dan kesadaran ditangguhkan sebagian atau seluruhnya serta fungsi tubuh sebagian dihentikan. ${ }^{(8)}$

Sebuah penelitian menunjukkan bahwa EDS dapat disebabkan oleh kualitas tidur yang buruk dan secara langsung mempengaruhi perilaku dan prestasi pekerja. ${ }^{(9)}$ Namun, hasil penelitian tersebut bertolak belakang dengan penelitian yang dilakukan oleh Giri, et al. yang menyatakan bahwa terdapat hubungan antara kualitas tidur dengan EDS pada mahasiswa fakultas kedokteran. ${ }^{(10)}$ Adanya hasil-hasil penelitian yang tidak konsisten memerlukan dilakukannya penelitian lebih lanjut. Penelitian ini bertujuan untuk menentukan hubungan antara kualitas tidur dan EDS pada pekerja bergilir. 


\section{METODE}

Penelitian ini menggunakan desain potong lintang dan dilakukan pada sebuah perusahaan antara tanggal 3 Februari sampai 10 Mei 2019. Sebanyak 57 pekerja diikutsertakan pada penelitian ini dengan kriteria inklusi adalah pekerja yang minum obat penenang (keterangan diperoleh dari dokter perusahaan). Subjek dipilih secara consecutive non-random sampling. Pengumpulan data karakteristik demografi dengan menggunakan kuesioner. Kualitas tidur subjek penelitian diukur menggunakan Pittsburg sleep quality index (PSQI) yang mencakup tujuh komponen dan terdiri dari 17 pertanyaan. Setiap pertanyaan diberikan skor antara 0-3 dan skor total dari PSQI adalah 21. Epworth sleepiness scale merupakan sebuah kuesioner yang digunakan untuk mengukur EDS yang mencakup 8 pertanyaan dan setiap pertanyaan diberikan skor antara 0-3 dan skor total EDS adalah 24.

Hasil uji normalitas data menunjukkan data yang dikumpulkan tidak terdistribusi secara normal. Uji korelasi Spearman digunakan untuk menguji hubungan antara kualitas tidur dan usia dengan EDS. Untuk membandingkan perbedaan EDS antara laki-laki dan perempuan dilakukan uji Mann Whitney. Penelitian ini memperoleh kelayakan etik (ethical clearance) dari Komisi Etik Riset Fakultas Kedokteran Universitas Trisakti dengan nomor 15/KER-FK/I/2019.

\section{HASIL}

Tabel 1. Distribusi karakteristik demografi, kualitas tidur dan excessive daytime sleepines (EDS) dari subjek $(n=57)$

\begin{tabular}{lccc}
\hline \multicolumn{1}{c}{ Karakteristik } & $\mathbf{n}$ & $\mathbf{\%}$ & Median \\
\hline Usia (tahun) & & & 27 \\
$20-29$ & 40 & 70.1 & \\
$30-39$ & 5 & 8.8 & \\
$40-49$ & 11 & 19.3 & \\
50-59 & 1 & 1.8 & \\
Jenis Kelamin & & & \\
$\begin{array}{l}\text { Laki-laki } \\
\text { Perempuan } \\
\text { Kualitas tidur }\end{array}$ & 44 & 77.1 & \\
$<8$ & 13 & 22.9 & \\
8-15 & 39 & 68.4 & 6 \\
EDS & 18 & 31.6 & \\
$<9$ & & & \\
$9-18$ & 41 & 71.9 & 6 \\
\hline & 16 & 28.1 & \\
\hline
\end{tabular}

Sebanyak 57 pekerja berhasil dikumpulkan selama penelitan. Median usia subjek penelitian adalah 27 tahun dan sebagian besar 40 (70.1\%) berusia antara 20-29 tahun. Sebanyak 44 (77.1\%) subjek adalah laki-laki. Sebanyak 18 (31.6\%) pekerja bergilir mengalami kualitas tidur yang buruk dan $16(28.1 \%)$ mengalami EDS. Nilai median dari EDS adalah 6 dan untuk kualitas tidur juga 6 (Tabel 1).

Uji korelasi Spearman menunjukkan terdapat korelasi positif sedang yang bermakna antara kualitas tidur dan EDS ( $\mathrm{r}: 0.545 ; \mathrm{p}: 0.000)$. Uji korelasi Spearman menunjukan terdapat korelasi positif lemah tetapi tidak bermakna antara usia dengan EDS (r:0.124; p:0.359) (Tabel 2).

Tabel 2 Hubungan usia, kualitas tidur dan excessive daytime sleepines pada pekerja bergilir

\begin{tabular}{lcc}
\hline \multicolumn{3}{c}{ Excessive Daytime Sleepiness } \\
\hline & $\boldsymbol{r}$ & $\mathbf{p}$ \\
Kualitas Tidur & 0.545 & $0.000^{*}$ \\
Usia & 0.124 & $0.359^{*}$ \\
\hline
\end{tabular}

*Uji korelasi Spearman

Berdasarkan hasil uji Mann whitney didapatkan nilai median EDS pada pria sebesar 6.00 dan pada wanita sebesar 9.00, tetapi tidak terdapat perbedaan yang bermakna antara nilai median EDS antara laki-laki dan perempuan $(p=0.396)$.

\section{PEMBAHASAN}

Hasil penelitian kami menunjukkan prevalensi EDS besarnya 28.1\% kualitas tidur yang buruk sebesar $31.6 \%$. Penelitian pada 207 pekerja bergilir di pabrik tekstil menunjukkan prevalensi EDS yang lebih besar yaitu sebesar $39.1 \%$ dan prevalensi kualitas tidur yang buruk sebesar $54.0 \% .^{(11)}$

Hasil studi kami menunjukkan korelasi positif sedang yang bermakna antara kualitas tidur dengan EDS pada pekerja bergilir. Hasil tersebut sesuai dengan penelitian yang memperlihatkan hubungan yang signifikan antara kualitas tidur dengan EDS pada mahasiswa. ${ }^{(10)}$ Penelitian sebelumnya juga menunjukkan adanya hubungan antara kurangnya kualitas tidur dengan EDS pada pekerja bergilir di instansi kesehatan. ${ }^{(3)}$ Kualitas tidur yang kurang dapat mempengaruhi status mental, aktifitas fisik dan penurunan fungsi kognitif. ${ }^{(12)}$ Namun penelitian yang dilakukan pada penderita yang sedang dalam pengobatan dengan hemodialisa menunjukkkan tidak ada hubungan antara EDS dan kualitas tidur. ${ }^{(13)}$ Hasil penelitian 
yang tidak konsisten dengan hasil penelitian kami dapat disebabkan adanya perbedaan subjek yang diteliti. Pada penderita yang sedang mengikuti program hemodialisa, kualitas tidur yang buruk seringkali berkaitan dengan asupan kafein, usia lanjut, depresi, penyakit kardiovaskular dan lamanya melakukan hemodilisa. ${ }^{(14)}$

Hasil penelitian sebelumnya memperlihatkan ada hubungan yang signifikan antara kerja shift denganEDS pada pekerja di rumah sakit. ${ }^{(15)}$ Pada penelitian tersebut menunjukkan skor EDS dan PSQI total lebih tinggi pada pekerja bergilir dibandingkan dengan pekerja non-shift. Hal ini mungkin bisa terjadi karena sebenarnya gangguan tidur pada individu yang bekerja di instansi kesehatan, baik itu pekerja bergilir atau non-shift sudah menjadi hal yang biasa.

Hasil studi kami menunjukkan terdapat korelasi positif lemah yang bermakna antara usia dengan EDS pada pekerja bergilir. Hasil penelitian lain menunjukkan hubungan antara kurangnya kualitas tidur dan usia pada pekerja kesehatan yang professional. ${ }^{(16)}$ Sebuah penelitian di Malaysia menyebutkan bahwa kurangnya kualitas tidur dan kondisi stress menyebabkan tingginya kejadian EDS pada usia muda pada mahasiswa kedokteran. (17) Penelitian lain menunjukkan tidak terdapat perbedaan antara usia dan EDS pada dokter yang bekerja di rumah sakit akademik. ${ }^{(18)}$ Hasil penelitian sebelumnya menunjukkan hubungan yang signifikan antara EDS dan kualitas tidur pada perempuan yang menjadi pekerja bergilir. ${ }^{(19)}$ Penelitian lain juga menunjukkan hubungan antara perempuan pekerja bergilir pabrik tekstil dengan kurangnya kualitas tidur sehingga menyebabkan EDS. ${ }^{(1)}$ Lebih dari itu juga diperlihatkan bahwa perempuan yang bekerja shift mengalami peningkatan IMT (Indeks Masa Tubuh), dan hal ini menyebabkan kurangnya kualitas tidur sehingga menimbulkan EDS. Selain itu usia yang makin tua juga menyebabkan peningkatan IMT sehingga menyebabkan EDS. ${ }^{(3)}$

Kualitas tidur yang buruk dan EDS dilaporkan berhubungan dengan penyakit kardiovaskular, kecelakaan lalu lintas, kinerja akademis yang buruk, dan tekanan psikologis. ${ }^{(20)}$ Seseorang pekerja bergilir berisiko mengantuk pada situasi yang membutuhkan perhatian tinggi. Dalam keadaan normal, seseorang yang sehat biasanya sangat mengantuk antara pukul 21:00-
23:00, namun seorang yang mendapat shift malam sangat mengantuk antara pukul 04:00-07:00. (21) Pada pekerja bergilir, kurangnya kualitas tidur adalah sebuah resiko dari pekerjaan yang harus diterima dan kebanyakan sudah mampu beradaptasi. Kebutuhan tidur setiap individu berbeda, sebagian orang mampu tidur sedikit untuk tetap bisa bekerja dengan maksimal dan ada pula yang butuh tidur lebih banyak agar bisa bekerja dengan maksimal. ${ }^{(22)}$ Dengan demikian, EDS yang disebabkan oleh gangguan irama sirkadian harus didiagnosis dan diobati untuk menjaga keselamatan.

Salah satu keterbatasan penelitian kami ini adalah rancangan penelitian yang digunakan merupakan rancangan potong silang yang tidak dapat menjelaskan adanya hubungan sebab akibat. Keterbatasan lainnya adalah tidak meneliti variabel lainnya seperti aktifitas fisik dan istirahat pada siang hari yang juga dapat mempengaruhi terjadinya EDS. Perlu dilakukan penelitian lebih lanjut dengan mengunakan desain prospektif untuk dapat menjelaskan adanya hubungan sebab akibat antara kualitas tidur dan EDS.

\section{KESIMPULAN}

Penelitian kami menunjukkan adanya korelasi positif sedang antara kualitas tidur dan EDS pada pekerja bergilir, tetapi tidak terdapat perbedaan nilai median EDS antara laki-laki dan perempuan.

\section{UCAPAN TERIMA KASIH}

Penulis mengucapkan terima kasih kepada para pekerja yang bersedia ikut pada penelitian dan kepada pembimbing dan tim penguji skripsi Fakultas Kedokteran, Universitas Trisakti.

\section{KONFLIK KEPENTINGAN}

Para penulis tidak mempunyai konflik kepentingan saat melakukan penelitian ini.

\section{KONTRIBUSI KEPENGARANGAN}

LA dan AH berkontribusi pada penyusunan konsep dan penulisan makalah. LA berkontribusi pada pengumpulan dan analisa data. AH berkontrubusi pada perbaikan makalah setelah di review. Semua penulis telah membaca dan menyetujui makalah yang terakhir. 


\section{REFERENSI}

1. Haile KK, Asnakew S, Waja T, et al. Shift work sleep disorders and associated factors among nurses at federal government hospitals in Ethiopia: a cross-sectional study. BMJ Open 2019;9:e029802. doi:10.1136/bmjopen-2019-029802.1.

2. Messenger $\mathrm{J}$ for Team Leader, Working Conditions Group. Working time and the future of work. Geneva : International Labour Office;2018.

3. Espuga M, Antonia MR, Ayora A, et al. Sleep habits and excessive daytime sleepiness in a population of spanish health care employees. J Sleep Disord Manag 4053.1510011.

4. Sack RL, Auckley D, Auger RR, et al. Circadian rhythm sleep disorders: Part II, advanced sleep phase disorder, delayed sleep phase disorder, freerunning disorder, and irregular sleep-wake rhythm. Sleep 2007;30:1484-501.

5. American Sleep Association. Excessive daytime sleepiness: causes, test and treatments. American Sleep Association: Arlington, Virginia; 2019.

6. Fadeyi BA, Ayoka AO, Fawale MB, et al. Prevalence, predictors and effects of shift work sleep disorder among nurses in a Nigerian teaching hospital. Sleep Sci Pract 2018 2:6. doi:10.1186/ s41606-018-0027-x.

7. Slater G, Steier J. Excessive daytime sleepiness in sleep disorders. J Thorac Dis 2012;4:608-16. DOI: 10.3978/j.issn.2072-1439.2012.10.07.

8. Dorland WA, Newman. Kamus kedokteran Dorland. 31th ed. Jakarta: Penerbit Buku Kedokteran EGC; 2010.

9. Hangouche AJE, Jniene A, Aboudrar S, et al. Relationship between poor quality sleep, excessive daytime sleepiness and low academic performance in medical students. Adv Med Educ Pract 2018:9 631-8. Available from: https://doi.org/10.2147/ AMEP.S162350.

10. Giri P, Baviskar MP, Phalke DB. Study of sleep habits and sleep problems among medical students of pravara institute of medical sciences Ioni, Western Maharashtra, India. Ann Med Health Sci Res 2013;3:51-4. doi.10.4103/2141-9248.109488.

11. Ghods K, Abdoallahpour A, Ahmadi M, et al. The relationship between sleep disorders and quality of life in rotating shift workers at a textile factory. Middle East J Rehabil Health Stud 2017; 4:e12289. doi: 10.5812/mejrh.12289.

12. Olson EJ, Drage LA, Auger RR. Sleep deprivation, physician performance, and patient safety. Chest. 2009;136: 1389-96. Available from: http://dx.doi. org/10.1378/chest.08-1952.

13. Shen Q, Huang X, Luo Z, et al. Sleep quality, daytime sleepiness and health-related qualityof-life in maintenance haemodialysis patients. J Int Med Res 2016; 44: 698-709. DOI: 10.1177/0300060515608296.

14. Turkmen K, Yazici R, Solak Y, et al. Healthrelated quality of life, sleep quality, and depression in peritoneal dialysis and hemodialysis patients. Hemodial Int 2012; 16: 198-206. doi: 10.1111/j.1542-4758.2011.00648.x.

15. Alshahrani SM, Baqays AA, Alenazi AA, et al. Impact of shift work on sleep and daytime performance among health care professionals. Saudi Med J 2017:38 : 846-51. doi.10.15537/ smj.2017.8.19025.

16. Anbazhagan S, Ramesh N, Nisha C, et al. Shift work disorder and related health problems among nurses working in a tertiary care hospital, Bangalore, South India. Indian J Occup Environ Med 2016:20:35-8. doi.10.4103/0019-5278.183842.

17. Zailinawati AH, Teng CL, Chung YC, et al. Daytime sleepiness and sleep quality among Malaysian medical students. Med J Malaysia 2009:64:108-10

18. Ozder A, Eker HH. The prevalence of excessive daytime sleepiness among academic physicians and its impact on the quality of life and occupational performance. Int J Occup Med Environ Health 2015;284:721-30. Available from: http://dx.doi. org/10.13075/ijomeh.1896.00367

19. Fatani A, Al-rouqi K, Towairky JA, et al. Effect of age and gender in the prevalence of excessive daytime sleepiness among a sample of the Saudi population. J Epidemiol Glob Health 2015;5:S5966. doi.10.1016/j.jegh.2015.05.005.

20. Asaoka S, Namba K, Tsuiki S, et al. Excessive daytime sleepiness among japanese public transportation drivers engaged in shiftwork. J Occup Environ Med 2010;52:813-8. doi.10.1097/ JOM.0b013e3181ea5a67.

21. Ohayon MM. From wakefulness to excessive sleepiness: What we know and still need to know. Sleep Med Rev 2008;12:129-4. doi.10.1016/j. smrv.2008.01.001.

22. Carley DW, Farabi SS. Physiology of sleep. Diabetes Spectr 2016;29:5-9. doi.10.2337/ diaspect.29.1.5. 